\title{
Risco e Saúde nos Locais de Trabalho*
}

\author{
MARLA LÍGIA RANGEL
}

\section{Introdução}

A preocupação com os chamados riscos ocupacionais é relativamente recente no campo da medicina social e somente a partir da década de 70 é que a medicina do trabalho vem se desenvolvendo no Brasil como um novo campo de prática. Isso se fez observar quando se puderam sentir, de modo mais dramático e oneroso, os efeitos dos riscos à saúde nos locais de trabalho, expressos especialmente pelos elevados índices de acidentes de trabalho.

Os estudos predominantes na subárea de saúde ocupacional denominam os fatores de risco como "riscos ocupacionais" e privilegiam análises matemáticas para o exame das relações que se tecem em torno dos riscos e que participam da determinação dos acidentes e doenças nos locais de trabalho. Tal perspectiva nos parece ao mesmo tempo incoerente, como ressaltou Almeida Filho, ${ }^{1}$ e restritiva.

Outras abordagens introduzem elementos mais dinâmicos e procuram resgatar o caráter social da produção dos riscos, via o estudo dos processos

* Trabalho realizado junto ao Departamento de Medicina Preventiva da UFBA, baseado na Dissertaçâao de Mestrado em Saúde Comunitária intitulada Cadê o meu Aumento ou Vou Causar Acidente - Um Estudo de Caso da Cultura do Risco numa Indústria Petroquímica, defendida em janeiro de 1993, no DMP/UFBA.

** Médica Sanitarista da Secretaria Municipal de Saúde de Campinas, São Paulo.

1. N. Almeida Filho, A Clínica e a Epidemiologia, Salvador, APCE/Abrasco, 1992. 
de trabalho. Destacam-se, sobretudo, as análises de Laurell e Marquez e Laurell e Noriega, ${ }^{2}$ em consonância com o "Modelo Operário Italiano", difundido na América Latina principalmente pelos estudos de Berlinguer e Oddone et alli. ${ }^{3}$

Essas abordagens, buscando ampliar o modelo explicativo das doenças ocupacionais, introduzem a expressão "cargas laborais" que agrupa os fatores de risco. Por meio dessa categoria, procura-se uma espécie de condensação, na forma de "carga", do conjunto de fatores em interação que participam da determinação dos eventos mórbidos nos locais de trabalho. Tenta-se romper com a perspectiva de fatores isolados de seus determinantes sociais. Nesse sentido, o enfoque do social revela-se priorizando a dimensão econômica, especialmente as estratégias do capital para extrair a mais-valia, ${ }^{4} \mathrm{e}$ a dimensão política, particularmente a política sindical. ${ }^{5}$

O propósito de estudar os determinantes sociais dos acidentes e doenças nos locais de trabalho, nos coloca a necessidade de examinar o conceito de risco, assim como, também, as formas de proteção e prevenção. Considerase, para esse exame, as complexas relações que se tecem em torno dos riscos nos locais de trabalho, sejam elas de natureza econômica, política, ideológica ou mágico-religiosa. $O$ risco é pensado, aqui, a partir de um exercício de aproximação com a etnometodologia, a qual propõe estudar a ordem social a partir da ação dos que dela participam. Nesse enfoque teórico, autores como Berger e Luckmann e Goffman, ${ }^{6}$ partindo dos pressupostos da fenomenologia, entendem a realidade como uma construção do homem:

A etnometodologia leva em consideração os três momentos que integram o processo dialético fundamental por que passam todas as sociedades: a exteriorização, a objetivação e a internalização. ${ }^{7}$ Por seu intermédio, os indivíduos interagem com seus contextos produzindo práticas e represen-

2. A. C. Laurell e M. Marquez, El Desgaste Obrero en México. Proceso de Producción y Salud, Colección Problemas de México, México, Ediciones Era, 1983; e A. C. Laurell e M. Noriega, Processo de Produção e Saúde, São Paulo, Hucitec, 1989.

3. G. Berlinguer, Medicina e Política, São Paulo, Cebes-Hucitec, 1978; G. Berlinguer,A Saúde nas Fábricas, Sāo Paulo, Cebes-Hucitec/Oboré, 1983; e I. Oddone et alli, Ambiente de Trabalho -A Luta dos Trabalhadores pela Saúde, São Paulo, Hucitec, 1986.

4. A. C. Laurell e M. Marquez, El Desgaste Obrero..., op. cit.

5. I. Oddone et alli, Ambiente de Trabalho..., op. cit.; e A. C. Laurell e M. Noriega, Processo de Produção..., op. cit.

6. P. Berger e T. Luckmann, A Construção Social da Realidade, Petrópolis, Vozes, 1976; e E. Goffman, A Representação do Eu na Vida Cotidiana, Petrópolis, Vozes, 1975.

7. M. C. L. Braga, Conceitos Fundamentais da Etnometodologia, Salvador, 1977, mimeo. 
tações sociais, as quais seriam, para Goffman,${ }^{8}$ a expressão que o indivíduo transmite — os símbolos verbais - e emite, que inclui uma ampla gama de ações decorrentes de razões diferentes da informação transmitida.

O momento da exteriorização é definido ten do como base a compreensão de que a sociedade é produto da atividade do homem, a partir da qual ele constrói o mundo da cultura. ${ }^{9}$ A partir dessa noção é que buscamos ver' o risco na atividade humana do trabalho.

O momento da objetivação, diz Braga, ${ }^{10}$ é o da transformação da cultura em realidade, o que o homem faz ao atuar em grupo. É o momento da relação do homem com o mundo objetivo, quando ele experimenta a coisa objetiva, praticando-a. É nesse momento que as características ou a natureza da coisa objetiva se impõe ao indivíduo, definindo, por seu lado, as formas das práticas e representações.

O momento seguinte é o do retorno, da internalização, quando o homem se apropria da mesma realidade e, subseqüentemente, transforma as estruturas do mundo objetivo em estruturas da sua consciência subjetiva.

É a partir dessa concepção que desenvolvemos o conceito de risco, buscando identificar a sua natureza, as suas características primeiras que se impõem objetivamente ao homem, para entender as possibilidades de construção de sua realidade em uma sociedade plural.

\section{Risco — imprecisão conceitual}

Risco e perigo são termos freqüentemente usados de modo indistinto. Tal imprecisão conceitual traz dificuldades para problematizar um e outro, quando tomados como objetos de estudo.

No campo científico, encontramos o risco definido de maneira variada: na economia e engenharia industrial ele é descrito como probabilidade de ocorrência de dano em um tempo ou número de ciclos operacionais, ou como variável múltipla prescrita, cercando a vida laborativa, que pode acarretar dano (azar).

A noção de risco como azar é construída ao lado da noção de perigo, em uma elaboração tautológica, em que risco se define por si mesmo:

8. E. Goffman, A Representação do..., op. cit., p. 12.

9. M. C. L. Braga, Conceitos Fundamentais..., op. cit., p. 6.

10. Idem. 
“[...] um risco pode estar presente, mas pode haver baixo nível de perigo devido às precauçōes. Assim um banco de transformadores de alta voltagem possui um risco inerente de eletrocussāo, uma vez que esteja energizado. H́á um alto nível de perigo se o banco estiver desprotegido, no meio de uma área de pessoas [...]".11

O risco tomado, assim, como característica do ambiente externo ao indivíduo, sendo, portanto, apenas objetivado, torna possível seu controle e redução a partir de uma intervenção programada sobre as condições objetivas. Essa noção não fica, contudo, isenta de derivações de ordem econômica, política e ideológica. Segundo Duclos ${ }^{12}$ ela se filia a uma concepção que J. Short chama de uma verdadeira indústria de análise do risco. Desenvolvida especialmente nos Estados Unidos, para ela são constituídos quadros comparativos de avaliação social dos riscos, que buscam exprimir a variação em termos monetários, desenvolvendo uma espécie de gerenciamento do mesmo. Isso, segundo Duclos, tem influenciado o modo de pensar dos atores em corpos profissionais distintos.

Por outro lado, no nível econômico, esse modo de ver o risco dá lugar a um novo ramo industrial de produção de equipamentos voltados para a proteção individual e coletiva.

No plano ideológico, dá substrato a dois conceitos que, baseados na doutrina de "concausalidade", informam as decisões jurídicas em caso de ocorrência de acidentes com trabalhadores: o ato inseguro e a condição insegura. Tais conceitos fragmentam, de forma artificiosa, um único momento do processo de trabalho.

A epidemiologia, voltada para a compreensão da distribuição e causalidade das doenças, utiliza o conceito de risco também pautada no modelo matemático. Almeida Filho e Rouqueyrol o definiram como "o correspondente epidemiológico matemático da probabilidade de ocorrência de um evento referido a um tempo e a uma população". ${ }^{13}$ Este conceito é similar ao anterior, permitindo enfocar apenas parte do fenômeno risco. As características da população e da doença (ou dano) são separadas em fatores que, combinados mediante relações matemáticas, dão estimativas de probabilidade de o dano ocorrer. Os "fatores" de risco são, desse modo, elementos fragmentados do indivíduo ou do seu meio sociocultural e estudados em uma relação matemática e naturalizada.

11. De Cicco e Fantazzini, Introdução à Engenharia de Segurança de Sistemas, Sāo Paulo, Fundacentro, 1979.

12. D. Duclos, La Construction Sociale du Risque: Le Cas des Ouvriers de la Chimie Face aux Dangers Industriels, Paris, Conservatoire National des Arts et Métiers, 1986.

13. N. Almeida Filho e E. Rouqueyrol, Introdução à Epidemiologia Moderna, Rio de Janeiro, Abrasco, 1990, p. 3. 
Assim, essas disciplinas definem o risco conferindo privilégio a algumas dimensões que são apenas fragmentos de uma totalidade complexa: relação número de ciclos operatórios ou tempos e dano, na engenharia e economia; relação população, doença e tempo, na epidemiologia.

No campo da epidemiologia, observam-se esforços de alguns autores em favor de um novo paradigma, reconhecendo a existência de uma crise epistemológica, que se revela de modo mais evidente quando são analisadas as ambigüidades, contradições, inconsistências em torno do conceito de risco, como bem ressaltou Almeida Filho. ${ }^{14}$

Quanto ao perigo, é definido por Cicco e Fantazzini expressando uma exposição relativa a um risco, que favorece a sua materialização em danos. ${ }^{15}$ No Novo Dicionário Aurélio da Língua Portuguesa, encontramos perigo significando circunstância, estado ou situação que faz prenúncio de um mal a alguém ou algo. O risco é definido como perigo mais possível que provável.

Deduz-se que, geralmente, perigo é conceituado como sinônimo de risco, pois este (no conceito matemático) se manifesta no próprio dano. Ou o risco é diferenciado do perigo, isentando-o da relação matemática, definindo-o como exposição, circunstância, estado, situação.

\section{Risco - uma construção social}

Pensar o risco como uma construção social, o distingue do perigo por ser aquele conhecido, experimentado e nomeado pelo homem, enquanto tal. O perigo, no nosso entender, é o que permanece desconhecido, invisível e inesperado. Porque existe enquanto construção social, tecido em meio a relações sociais é que o risco pode ser mensurado, matematicamente, e sobre suas relações é possível intervir.

Porém, o caráter de virtualidade e de liminaridade é comum a ambos. O perigo distingue-se do risco por antecedê-lo e estar contido nele, encontrandose em todas as situações, tanto de insegurança como de segurança.

No campo das Ciências Sociais, o conceito de risco como relação matemática tem sido rejeitado por diversos autores. Douglas ${ }^{16}$ ao analisar questões relevantes aos limites de aceitação do risco por populações expostas, tece uma crítica bastante abrangente às abordagens matemáticas e planificadoras e intro-

14. N. Almeida Filho, A Clínica e a..., op. cit., p. 124.

15. De Cicco e Fantazzini, Introdução à Engenharia..., op. cit., p. 61 .

16. M. Douglas, Risk Acceptability According to the Social Sciences, Londres, Routledge \& Kegan Paul, 1985. 
duz novos elementos socioantropológicos para problematizar o tema, tais como: status social, nível cultural, literário, acesso às fontes de crédito, fatores embutidos em redes de parentesco e outros relacionados à identidade dos sujeitos. Também Duclos e outros pesquisadores da área de engenharia, como Lagadec e Sevá Filho, ou ergonomistas, como Wisner, têm buscado outras relações, que não somente as matemáticas, para tratar da questão do risco em suas disciplinas. ${ }^{17}$ Duclos ${ }^{18}$ enfatiza as dimensões simbólica e prática na conformação da prevenção dos riscos. Para ele, os fatores propriamente psicológicos, cognitivos e defensivos articulam-se com as relações políticas e ideológicas dentro das empresas.

O propósito de nos aproximarmos dessa discussão e entender a realidade dos riscos, a partir de quem os vivencia, nos coloca a questão da própria natureza do risco enquanto fenômeno social. Duas características lhe são próprias e possuem implicações na construção de sua realidade: a virtualidade e a liminaridade. Vejamos que conseqüências podem ter.

\section{Fenômeno virtual}

Tal como definido no Novo Dicionário Aurélio, ser virtual é "existir como faculdade, porém sem exercício ou efeito atual; suscetível de se realizar; potencial". Assim, a condição de virtualidade define-se enquanto algo que pode vir a ser sem ser ainda. Está presente em estado latente, podendo ou não se manifestar.

O risco encerra, pelo seu caráter de virtualidade, uma relação poder/saber que se constitui a partir das experiências dos homens para conhecê-lo e dominá-lo. A possibilidade de dominação exerce sempre um certo fascínio sobre o homem, porque vai ao encontro dos seus interesses e necessidades para a vida. Diante do risco o homem constrói um saber; em face do perigo o homem teme e anseia. ${ }^{19}$

17. D. Duclos, La Construction Sociale..., op. cit.; P. Lagadec, La Civilization du Risque Catastrophes Technologiques et Responsabilité Sociale, Paris, Éditions du Seuil, 1981; A. O. Sevá Filho, No Limite dos Riscos e da Dominação: A Politização dos Investimentos Industriais de Grande Porte, Tese de Livre Docência, Instituto de Geociências/Unicamp, 1988; e A. Wisner, Le Travailleur Face aux Systèmes Complexes et Dangereux, Collogne de Chantilly, s/e, 1986.

18. D. Duclos, La Construction Sociale..., op. cit.

19. C. Dejours, A Loucura do Trabalho: Estudo de Psicopatologia do Trabalho (Trad. A. I.

- Paraguay e L. L. Ferreira), São Paulo, Cortez-Oboré, 1987. 
A relação poder/saber, em torno dos riscos no trabalho, nos remete para as relações de natureza política e ideológica que aí ocorrem. O saber e o poder estão implicados mutuamente pois, como nos mostra Foucault, não há relação de poder sem que se constitua um campo de saber, nem o contrário, pois todo saber constitui novas relaçōes de poder. ${ }^{20}$

A distribuição desigual de poder, em uma sociedade de classes, é acompanhada de uma distribuição também desigual de saber. Do mesmo modo, como a percepção do risco vincula-se ao saber, a sua realidade subjetiva obedecerá à distribuição desigual deste, enquanto o perigo, por estar desvinculado do saber, tem sempre uma margem que intimida a todos igualmente. Assim, o risco intimida os grupos sociais que ainda o têm como perigo, isto é, que ainda não o conhecem, devido a uma distribuição desigual do saber e de sua nomeação como tal.

Para Castel, ${ }^{21}$ o limite entre risco e perigo na doença mental apresenta-se sob a forma de uma percepçāo da mesma como suscetível de uma passagem ao ato imprevisível e violento. $O$ perigo, nesse caso, seria uma noçāo misteriosa, qualidade imanente do sujeito, mas cuja existência é aleatória, pois a prova objetiva nunca é dada logo após sua realizaçāo. $O$ autor ressalta que o diagnóstico da periculosidade recoloca a categoria do possível sobre a do real, sob o pretexto de que o possível é mais ou menos provável.

Sevá Filho, 22 ao analisar as circunstâncias que se delinearam em condições concretas onde ocorreram acidentes trágicos de origem tecnológica, afirma que as normas de segurança e os limites operacionais de instalaçāo e dos equipamentos são conhecidos apenas por uma parte restrita dos técnicos, geralmente aqueles mais qualificados.

O risco como construção social consciente e deliberada tem a sua realidade ordenada de modo bastante diversificado, dependendo não só da distribuição do saber sobre ele, mas dos jogos de interesses que definem as relações políticas onde ele está presente. Tanto serão distintas as construções do conceito de risco, como as elaboraçōes de formas de controle e das relaçōes em torno dele, importando, para essas construçōes, a identidade dos sujeitos e os valores socioculturais neles investidos.

Destacamos, até aqui, o caráter virtual do risco. Tal caráter nos permite pensar de que modo as práticas e representaçōes em torno do risco sāo modificadas pelas relações de poder/saber.

20. M. Foucault, Microfisica do Poder, Rio de Janeiro, Graal, 1979.

21. R. Castel, La Gestion des Risques, Paris, Éditions de Minuit, 1981.

22. A. O. Sevá Filho, No Limite dos Riscos..., op. cit., p. 101. 


\section{Fenômeno liminar}

Um outro aspecto da natureza do risco que nos interessa ressaltar é o seu caráter liminar. Como entidade liminar que é, o risco coloca-se em meio a dois momentos polares de processos como: saúde e doença, segurança e insegurança, vida e morte, constituindo-se em um atributo ambíguo e indeterminado em relação a eles. ${ }^{23}$ Tal ambigüidade e indeterminação tornam a exposição a momentos ou a situações de risco revestida de especial tensão e atenção.

Estar sob risco é estar sob suspeita de ter deixado de ser um sem ser ainda o outro. É um estado de incerteza, que se define pela experiência de ritos de passagem de um pólo a outro do processo, em que o homem passa a nomear uma situação como arriscada ou não e a construir formas de proteção e prevenção. Por intermédio dos ritos de passagem, a situação é separada de um pólo para ser agregada a outro. ${ }^{24}$

As polaridades saúde e doença, segurança e insegurança, vida e morte, são também construções sociais e, como tais, definidas pelos valores socioculturais dos sujeitos.

A noção de saúde vincula-se a um estado de normalidade do corpo. Mas ser normal ou patológico são condições definidas socialmente por um conjunto de normas que exprimem apenas distinções, outras formas de vida possíveis e gradações. Canguilhem ${ }^{25}$ chama a atenção para o fato de que as normas humanas são determinadas como possibilidades de agir de um organismo em situação social, e não como funções de um organismo encarado como mecanismo vinculado ao meio físico. Ressalta que a forma e as funções do corpo humano são principalmente a expressão dos modos de viver socialmente adotados pelo meio. ${ }^{26}$

Como mudam os valores culturais e científicos, os critérios que definem saúde e doença são mutáveis não apenas em sociedades distintas, mas em uma mesma sociedade em tempos diversos ou em diferentes grupamentos sociais.

Berlinguer, em A Doença, ${ }^{27}$ mostra como essa entidade sofre variações culturais tanto na sua definição, quanto na sua função social. Ela pode ser interpretada socialmente como culpa, sofrimento, privilégio, punição etc.

23. V. W. Turner, O Processo Ritual - Estrutura e Antiestrutura, Petrópolis, Vozes, 1974, p. 117.

24. A. Van Gennep, Os Ritos de Passagem, Petrópolis, Vozes, 1978.

25. G. Canguilhem, O Normal e o Patológico, Rio de Janeiro, Forense Universitária, 1978, p. 113.

26. Idem, p. 244

27. G. Berlinguer, $A$ Doença, Sāo Paulo, Cebes/Hucitec, 1988. 
Sontag 28 analisa a tuberculose e o câncer como metáforas, por meio das quais o homem usa a doença como um valor fora do universo clínico. Em diversas culturas mantêm-se, sobre o fenômeno doença, formas de pensamento mágico que tornam possível a metáfora.

A doença pode ser também referida a uma relação econômica como o fazem Laurell e Marquez ${ }^{29}$ ao tratá-la como o desgaste da força de trabalho - um valor econômico - pelo capital. Neste caso, a doença é concebida como a expressão da ausência de integridade da força de trabalho, que foi desgastada, ou consumida pelo capital no processo de trabalho, para além daquilo que o capitalista compra e deve repor mediante o pagamento do salário.

Assim como saúde e doença, o sentido de segurança e insegurança é igualmente variável. O sentir-se seguro pode ter razões físicas ou metafísicas. A segurança pode estar ligada à utilização de tecnologia apropriada ou de outros elementos simbólicos, não necessariamente objetivos. Fazer o sinal da cruz pode ser uma boa medida de segurança para enfrentar uma situação de risco. Verificar a sua eficácia ou tentar testá-la empiricamente não é o que está em questão, já que o significado central de um rito, de um comportamento mágico, é expressivo, constituindo-se em um fim em si mesmo. ${ }^{30}$ A sorte ou a ajuda divina nesses casos são freqüentemente apelos humanos, conscientes ou inconscientes. Beattie ${ }^{31}$ nos diz que a magia não é apenas uma maneira de pensar sobre as coisas, mas também de fazer as coisas. Ainda segundo ele, as pessoas recorrem a ela em situações de perigo ou infortúnio real ou potencial, pois se tudo estivesse ótimo, no melhor dos mundos possíveis, haveria pouca necessidade de magia ou de religião. Para esse autor o comportamento ritual "mágico-religioso" pode fornecer um modo de enfrentar situações de infortúnio ou perigo com as quais não há outros meios de lidar. Fazer qualquer coisa em face de um desastre real, ou de sua ameaça, é satisfatório psicologicamente, e é um meio de aliviar a ansiedade. $\mathrm{O}$ autor relaciona o comportamento com o corpo de conhecimentos que os indivíduos possuem. Ressalta que na ausência de um corpo de conhecimentos empíricos ao qual apelar como auxílio, ou quando o mesmo é inadequado, os procedimentos rituais, cuja validade não está na experiência, podem fornecer uma alternativa aceitável.

28. S. Sontag, A Doença como Metáfora (Trad. M. Ramalho), Rio de Janeiro, Graal, Coleçāo Tendências, vol. 6, 1984.

29. A. C. Laurell e M. Marquez, El Desgaste Obrero..., op. cit.

30. J. Beattie,Introdução à Antropologia Social, São Paulo, Companhia Editora Nacional, 1977, p. 241.

31. Idem, p. 245 
Também no que se refere a vida e a morte não encontramos uniformidade conceitual, embora as margens de diferenciação cultural se estreitem quanto a esses fenômenos, já que eles unificam e equalizam os seres humanos.

Ziegler, em Les Vivants et la Mort, ${ }^{32}$ mostra as diferenças existentes entre a cultura africana e a medicina ocidental para definir a morte. Enquanto esta última se utiliza de sinais clínicos para determinar o instante da morte, este momento está ausente na tanatopráxis nagô. Isto porque para esses povos, segundo Ziegler, o homem não deixa nunca de existir, permanecendo vivo de algum modo, seja dançando a roda dos Orixás, quando vivo, ou realizando o périplo noturno, ou ainda, em algumas ocasiōes, se apoderando de outro homem em transe e falando, por seu intermédio, a seus descendentes.

Os diferentes momentos polares dos processos de vida dos indivíduos são, todos eles, integrantes de universos sociais, sendo, portanto, indissociáveis de concepções mágicas, que também pode participar da construção da realidade do risco.

Enfocando a doença, o acidente e a morte em relaçāo ao risco, estes significam momentos de ruptura e redefinição. Isto é, uma vez instalado um desses fenômenos, os homens reconhecem a situação como de risco, podendo acrescentá-la à sua experiência anterior e constru ir novas noçōes de risco e de proteçāo.

A possibilidade de mudança súbita de um pólo a outro do processo, mais particularmente com a ocorrência de um acidente fatal ou não, recobre as situações de risco de sentimentos de insegurança, angústia, desconforto e desconfiança. Esse espaço de virtualidade negativa pode dar lugar a construções fantasmáticas que funcionam como mecanismos para contornar esses sentimentos e reduzir-lhes os efeitos. Tais contornos e reduções se dão à medida que esses sentimentos são reconhecidos e, de algum modo, nomeados, conferindo-lhes realidade e, também, permitindo o exercício de alguma prática sobre eles.

\section{Risco nos locais de trabalho}

A depender dos jogos sociais e dos traços socioculturais dos sujeitos, existentes nos locais de trabalho, os riscos de acidentes e doença podem assumir acepções distintas para os diferentes atores sociais. Tais significa-

32. J. Ziegler, Les Vivants et la Mort, Paris, Éditions du Seuil, 1975, p. 65. 
dos podem ser definidos de maneiras diferentes, ocultados ou enfatizados. Duclos, em La Construction Sociale du Risque, ${ }^{33}$ ao estudar os riscos em indústrias químicas da França e Estados Unidos, a partir da aplicação de uma enquete entre operadores, depara-se com formas distintas de percepção dos riscos. Estas vão da negação dos riscos incorridos até a eufemização e a ênfase, percorrendo discursos de autovalorização, de dramatização reivindicante e relativização individualista.

Desse modo, a teoria nos permite afirmar que os riscos no trabalho podem ter significados com base não apenas em relações econômicas, mas no conjunto de relações complexas que se dão no processo de trabalho, sejam elas econômicas, políticas ou ideológicas. Elas produzem práticas e representações sociais não homogêneas, mesmo em uma mesma categoria de trabalhadores, em função das diferenças socioculturais dos sujeitos, conformando culturas de risco específicas.

A relação do homem com o perigo está intrinsecamente ligada aos processos de trabalho, desde o seu momento mais original. ${ }^{34}$ As experiências humanas com matérias-primas de natureza diversificada, assim como as formas de obtenção e armazenamento das mesmas, e os tipos de fluxos produtivos forjados pela tecnologia, constroem uma gama bastante variada de riscos originados dessa relação. Também a organização do trabalho é capaz de criar novas situações em que este é executado sob condições de perigo, dando origem a novos riscos. Diversos autores têm evidenciado os efeitos dessas mudanças sobre a saúde dos trabalhadores. ${ }^{35}$

Para o estudo do risco nos locais de trabalho, contudo, importa distinguir a noção de processo produtivo daquela de processo de trabalho, e resgatar as múltiplas dimensões deste último: as de natureza política, econômica, ideológica, bem como a que diz respeito à intersubjetividade dos atores.

$O$ enfoque do processo de trabalho que nos interessa, se dá no sentido de apreender as relações que se tecem em torno do risco e que contribuem para a construção de sua realidade e, conseqüentemente, das práticas e representações que se configuram socialmente.

33. D. Duclos, La Construction Sociale..., op. cit.

34. E. R. Service, Os Caçadores, Rio de Janeiro, Zahar, 1975; e G. Clark, A Pré-História, Rio de Janeiro, Zahar, 1975.

35. M. J. B. Moran, “Enfermidades Profesionales”, in A. T. Jimenez, coord., Enfermidad y Clase Obrera, México, D.F., Unidad Profesional Sto. Tomas, junho de 1982; Diesat - H. P. Ribeiro e F. A. C. Lacaz, orgs., De que Adoecem e Morrem os Trabalhadores, Sāo Paulo, Diesat, 1984; Diesat - A. J. A. Rebouças et alli, Insalubridade: Morte Lenta no Trabalho. A Insalubridade no Brasil, Sāo Paulo, Oboré Editorial, 1989. 
A recente aproximação da Sociologia do Trabalho da Antropologia, sugerida por autores como Kaplinsky, Zarifian ${ }^{36}$ e apropriada por Leite, Fleury e Valle, ${ }^{37}$ tem revelado novas possibilidades analíticas para o conhecimento dos processos de trabalho o que, sem dúvida, poderá contribuir para o estudo dos riscos e da saúde nos locais de trabalho.

\section{Consideraçóes finais}

O enfoque do risco como uma construção social nos oferece ricas possibilidades analíticas para o estudo do processo saúde/doença, sobretudo, porque nos dá a chance de perceber e explicar as diferentes maneiras como os indivíduos se relacionam com as situações de risco nos locais de trabalho, valorizando-se as construções próprias das pessoas e dos grupos sociais.

O estudo do processo de trabalho, enquanto cenário em que tal realidade é construída, pode se revelar frutífero, sobretudo quando se enfoca as múltiplas relações desse processo e não apenas as de natureza técnica e política. Os riscos podem ter significados baseados no conjunto de relações que se tecem na vida social, sejam elas de natureza econômica, política, ideológica ou mágico-religiosa, produzindo práticas e representações não homogêneas, ainda que em um mesmo grupo social. Tais significados definem, de algum modo, a forma como os sujeitos se colocam nas situações de risco, como o reconhecem e como se protegem.

As noções de identidade e de subjetividade poderão, por sua vez, nos conduzir ao entendimento da participação dos indivíduos na construção da realidade dos riscos, da cultura específica, e elucidar os meios pelos quais e processa a ação social em torno dos riscos.

36. R. Kaplinsky, Restructuring the Capitalist Labour Process: Some Lessons from the Automobile Industry, Brighton, IDS/University of Sussex, s/d; e P. Zarifian, Simbolisation et Produtivité, Trabal ho apresentado no seminário Processo de Trabalho e Produçāo Simbólica, Sāo Paulo, USP/BID, 1989.

37. M. Leite, A Vivência Operária da Automaçāo Microeletrônica, Tese de Doutorado em Sociologia, USP, 1990; M. T. Fleury, “A Produçāo Simbólica das Organizaçōes”, in Padrões Tecnológicos e Políticas de Gestão, s/l, s/d; M.T. Fleury, “Estórias, Mitos, Heróis - Cultura Organizacional em Relaçāo de Trabalho”, Revista de Administração de Empresas, vol. 27, $\mathrm{n}^{2} 4$, outubro/dezembro de 1987, pp. 7-18; e R. Valle, Automaçāo Comparada: A Indústria na França, na Alemanha e no Brasil, Trabalho apresentado no XII Encontro Anual da Anpocs, Caxambu, MG, 22-26 de outubro de 1990. 


\section{RESUMO}

\section{Risco e Saúde nos Locais de Trabalho}

O artigo apresenta uma exploração crítica do conceito de risco no campo da medicina social, em especial o chamado risco ocupacional, mediante uma aproximação com a etnometodologia. O estudo do risco como fenômeno sociocultural revela relações de natureza diversa que o cercam, nem sempre passíveis de serem compreendidas por abordagens matemáticas, tradicionalmente estabelecidas pelos enfoques da epidemiologia e engenharia de segurança. São relações do tipo econômico, político, ideológico ou mágicoreligioso que são vividas em situações particulares e cenários definidos, onde práticas e representações sociais se estruturam, conferindo realidade aos riscos.

\section{ABSTRACT}

\section{Work-place Risks and Health}

The article explores the concept of risk within the field of social medicine, particularly in relation to the work place. The concept is examined in terms of the imprecision with which it has been employed in the scientific field as well as in terms of its phenomenal characteristics of virtuality and threshold. With these characteristics in mind, the text also explores how health risks can have distinct meanings within the dynamics of the work process, in all its multiple dimensions.

\section{RÉSUMÉ}

\section{Risque de Santé dans les Locaux de Travail}

L'article explore sous un angle critique, au moyen d'une approche ethnométhodologique, le concept de risque dans le domaine de la médecine sociale, spécialement ce qu'on appelle le risque du travail. L'étude du risque comme phénomène socio-culturel, révèle des relations de nature diverse qui l'entourent, pas toujours compréhensibles par des approches mathématiques traditionnellement mises en évidence par l'épidémiologie et 
l'ingénierie de la sécurité. Ce sont des relations de type économique, politique, idéologique où macro-religieux, qui sont vécues dans des situations particulières et des scénarios bien définis où les pratiques et les relations sociales se structurent, donnant aux risques leur caractère réel. 